Quality contributed papers will enliven the Charlotte conference. Attendees will be buzzing with comments about the thoughtprovoking presentations they have heard. Creating a successful abstract can be easy if the suggestions above are noted.

Contributed papers are due on May 31, 2002. The Call for Participation is available online at http://www.ala.org/acrl/charlotte/ cfp.html. Abstracts of 250 to 500 words should be sent to: Gloriana St. Clair, University Librarian, Carnegie Mellon University Libraries, 4909 Frew Street, Pittsburgh, PA 15213-3890; (412) 268-2447; fax (412) 268-2793; e-mail: gstclair@andrew. cmu.edu.

\title{
Tips for successful workshops
}

\author{
by Rosemary McAndrew and Susan Richards
}

$\mathbf{R}$ emember the workshops at the 2001 ACRL National Conference in Denver? Innovative, engaging, focused, these workshops were an opportunity to concentrate on one issue or topic for an extended period of time. Four of these workshops were offered in Denver for the first time, and participants gave them rave reviews. As you contemplate the development of a workshop for the 2002 conference, keep in mind the following:

- Workshops are three-hour sessions.

- During this lengthy session, you will be able to engage your audience in a variety of active learning exercises.

- Participants expect to develop a new skill, plan, or program.

- Limit the number of workshop facilitators. Remember, learning, not presenting, is key. (This is not an opportunity for a large number of presenters to impart information. It is a chance for attendees to actively take part in a learning opportunity.)

- Limit the content. While you have three hours, it is better to cover less information in-depth than to overload the participants with information.
- Clarify your format and the learning outcomes you expect to accomplish. Ask how you will encourage participation. What will the participants learn or take away at the end of the workshop?

- Let your imagination fly. Here is a chance to develop an interactive learning experience for librarians who are eager to engage in a topic you chose.

At the Denver conference, workshop participants developed marketing plans, created library faculty collaborations, devised plans for partnerships, and assessed their information literacy initiatives. A workshop is more than a focused discussion. Those who participate will expect to have something to show for their time and effort. Is there a tangible, like a written policy or plan, that attendees will complete at the end of the workshop? Is there a particular skill or set of skills participants will develop during the workshop?

We know you have a workshop idea that will help all of us "Learn to Make A Difference." Send in that application by May 31, 2002. The Call for Presentations is available online at http://www.ala.org/acrl/ charlotte/cfp.html.

\section{About the authors}

Rosemary MCAndrew is reference librarian and department chair at the Community College of Philadelphia, e-mail: rmcandrew@ccp.cc.pa.us, and Susan Richards is university librarian at Lawrence University, e-mail: susan.l.richards@lawrence.edu 